\title{
O Bem Viver como uma Alternativa de Reconfiguração de Cidades Brasileiras
}

\author{
El Buen Vivir como una Alternativa de Reconfiguración de Ciudades \\ Brasileñas
}

Good Living as an Alternative for Reconfiguration of Brazilian Cities

\author{
Fernanda Rodrigues Lagares ${ }^{1}$ \\ Cassyo Lima Santos ${ }^{2}$ \\ Katiúcia da Silva $\operatorname{Nardes}^{3}$
}

\begin{abstract}
Resumo
O objetivo deste trabalho é contribuir para a reflexão acerca da possibilidade de se reconfigurar cidades brasileiras a partir do Bem Viver, filosofia que questiona o conceito eurocêntrico de bem-estar e que pode ser entendida como verdadeiro enfretamento à colonialidade do poder ao regressar a valores de uso, se opor ao conceito de acumulação perpétua e propor harmonia com a natureza, relacionalidade, reciprocidade, solidariedade e complementariedade entre indivíduos e comunidades. Diante da atual crise civilizatória e ambiental provocada pelo capitalismo e seu suporte ideológico calcado no individualismo e no racionalismo, além do espaço que a mesma possibilitou à concepções de desenvolvimento distintas das do capitalistmo e às experiências ecossocioeconômicas, se faz necessário discutir as configurações do maior símbolo de desenvolvimento, na concepção capitalista do termo: das cidades. No caso do Brasil, essa discussão se torna ainda mais urgente, pois o processo de fundação das primeiras cidades brasileiras, ocorrido a partir da geração de colônias, marcado por invasões e despossessão das populações locais e de exploração de seus territórios, trouxe sérias consequências às configurações de muitas das cidades atuais, condenando-as a reproduzirem os modos de vida dominantes, coloniais, modernos e capitalistas, e as fazendo incapazes de abrigar modos de vida adequados aos interesses das diferentes comunidades que compõem o povo brasileiro e as habitam.
\end{abstract}

Palavras-Chave: Bem Viver, Desenvolvimento, Reconfiguração da Cidade.

\section{Resumen}

El objetivo de este trabajo es contribuir para la reflexión sobre la posibilidad de reconfigurar las ciudades brasileñas a partir del Buen Vivir, filosofía que cuestiona el concepto eurocéntrico de bienestar y que puede ser entendida como verdadero enfrentamiento a la colonialidad del poder al regresar a valores de uso, al oponerse al concepto de acumulación perpetua y proponer armonía con la naturaleza, relacionalidad, reciprocidad, solidaridad y complementariedad entre individuos y comunidades. Ante la actual crisis civilizatoria y ambiental provocada por el capitalismo y su aporte ideológico basado en el individualismo y en el racionalismo, además del espacio que ha posibilitado las concepciones de desarrollo distintas de las del capitalismo y las experiencias ecosocioeconómicas, se hace necesario discutir las configuraciones del mayor símbolo de desarrollo, en la concepción capitalista del término: de las ciudades. En el caso de Brasil, esa discusión resulta aún más urgente, dado que el proceso de fundación de las primeras ciudades brasileñas, que tuvo lugar a partir de la generación de colonias, marcado por invasiones y desposesión de la población local y de explotación de sus territorios, ha traído serias consecuencias a las configuraciones de muchas de las actuales ciudades, en que están condenadas

\footnotetext{
1 Mestranda em Estudos de Cultura e Território - Universidade Federal do Tocantins - UFT. Campus Araguaína-Tocantins, Brasil; fernanda.lfcg@gmail.com.

2 Mestrando em Estudos de Cultura e Território - Universidade Federal do Tocantins - UFT. Campus Araguaína-Tocantins, Brasil; cassyosantos@hotmail.com

3 Mestranda em Estudos de Cultura e Território - Universidade Federal do Tocantins - UFT. Campus Araguaína-Tocantins, Brasil; katiucia.nardes@ifto.edu.br
} 
a reproducir los modos de vida dominantes, coloniales, modernos y capitalistas, y las hacen incapaces de abrigar modos de vida adecuados a los intereses de las diferentes comunidades que componen a la población brasileña que las habitan.

Palabras claves: Buen Vivir, Desarrollo, Reconfiguración de la Ciudad.

\section{Abstract}

The objective of this work is to contribute to the reflection about the possibility of brazilian cities reconfiguring from the Good Living, a philosophy that questions the eurocentric concept of welfare and can be understood as a true coping to the coloniality of the power when returning to the use values, oppose the concept of perpetual accumulation and propose harmony with nature, relational, reciprocity, solidarity and complementarity between individuals and communities. Faced with the current civilization and environmental crisis provoked by capitalism and its ideological support based on individualism and rationalism, in addition to the space that it has enabled development conceptions different from those of capitalistism and to ecossocioeconomic experiences, it is necessary to discuss the configurations of the greatest Developmentsymbol, in the capitalist conception of the term: of cities. In the case of Brazil, this discussion becomes even more urgent, since the process of founding the first brazilian cities, which occurred as a result of the colonization, marked by invasions and dispossession of the local populations and exploitation of their territories, brought serious consequences to the configurations of many of today's cities, condemning them to reproduce the dominant, colonial, modern and capitalist ways of life, rendering them incapable of harboring modes of life adequate to the interests of different communities that compose and inhabit the Brazilian people.

Keywords: Good Living, Development, City Reconfiguration.

\section{Introdução}

O presente trabalho busca refletir, por meio de revisão bibliográfica, acerca da possibilidade de se reconfigurar parte das cidades brasileiras a partir da filosofia do Bem Viver. Com a atual crise civilizatória e ambiental provocada pelo capitalismo e seu suporte ideológico calcado no individualismo e no racionalismo, além do espaço que a mesma possibilitou à concepções de desenvolvimento distintas das do capitalismo e às experiências ecossocioeconômicas, se faz necessário discutir as configurações do maior símbolo de desenvolvimento, na concepção capitalista do termo: das cidades, sobretudo em razão do distanciamento que o seu reconhecimento enquanto lugar privilegiado, moderno e desenvolvido tem trazido aos modos de vida das populações tradicionais.

Embora a filosofia do bem viver ainda seja um objeto tímido nas discussões acadêmicas, quando se trata dessa mesma discussão considerando o espaço urbano, sua presença se torna ainda mais rara, talvez em razão do fato de o próprio ambiente acadêmico viver sob os ditames do sistema capitalista. Isso, somado à dificuldade de se pensar em reconfigurações de cidades, faz com que este trabalho limite seus objetivos à contribuir com a introdução das discussões que apresenta, de modo que, entendendo que esta não pode se dar de outra maneira, nos escusamos da necessidade de tratar o tema urbano com extremo rigor e da pretensão de oferecer respostas imediatas - e nos limitamos a levantar provocações. 
Portanto, neste artigo, refletiremos sobre a configuração das cidades brasileiras atuais considerando seu processo de origem e as consequências que suas características geram às comunidades que possuem modos de vida diferentes dos dominantes (coloniais, modernos e capitalistas) e a possibilidade de, diante da crise civilizatória e ambiental provocada pelo capitalismo e seu suporte ideológico calcado no individualismo e no racionalismo, além do espaço que a mesma possibilitou à concepções de desenvolvimento distintas das do capitalistmo e às experiências ecossocioeconômicas, configurar parte delas elegendo a filosofia do bem viver como horizonte.

\section{2. $O$ capitalismo e as cidades brasileiras}

Faustel de Coulanges (1961), no prefácio de sua obra "A Cidade Antiga”, faz um alerta aos perigos do hábito que mantemos, inclusive a partir do nosso sistema educacional, de continuamente compararmos nossa história à dos gregos e romanos e explicarmos nossas revoluções pelas suas, inclusive explicitando, dentre outros, o fato de que, observando mal as instituições da cidade antiga, já se quis fazê-las reviver entre nós.

Atualmente, mesmo não mais desejando reviver as cidades antigas, e ainda que as comparações com Roma e Grécia sejam por muitas vezes substituídas ou intermediadas por comparações com outras grandes potências europeias, acreditamos que elas sejam a razão de, no Ocidente, as cidades serem tomadas enquanto símbolos de desenvolvimento e progresso.

Assumindo também a perspectiva de que as cidades são tidas como símbolo de desenvolvimento e progresso, Williams (1990) afirma que, enquanto modo de produção, o capitalismo é o processo básico por trás da maior parte da história da cidade que se conhece: "Ao longo de séculos, seus impulsos econômicos abstratos, suas prioridades fundamentais no campo das relações sociais, seus critérios de crescimento, lucro e prejuízo vêm alterando nosso campo e criando os tipos de cidade que conhecemos" (Williams, 1990 p.404); e Harvey (2009), denunciando a forma como o capital opera nas cidades e a quantidade de direitos que consegue exercer sobre elas, diz que as cidades, mais do que por pessoas, foram regidas pelo capital. Sua crítica se dirige ao desenvolvimento capitalista descontrolado e à expansão interminável e desordenada financiada por ele, independentemente das consequências sociais, ambientais ou políticas geradas e, ao tratar do direito à cidade, defende que lutar por ele é também lutar contra o capital (HARVEY, 2014).

Tratando especificamente do Brasil, e considerando as consequências das influências externas, seja pelo mencionado hábito de comparação e/ou pela intervenção direta 
de outros países, é importante pensarmos no processo de fundação das primeiras cidades brasileiras, as quais se deram a partir da geração de colônias, de invasões e despossessão das populações locais e de exploração de seus territórios. A colonização brasileira não pode ser tratada como uma corrente migratória, ela foi acompanhada de um verdadeiro massacre ecológico e populacional.

Ibánez (2016), ao discorrer sobre as cidades, não necessariamente brasileiras, mas que tiveram esse mesmo processo fundador, afirma que as características acima mencionadas, assim como a colonialidade em suas vidas, permanecem até hoje e que, como por condenação da Colônia, as cidades, reproduzindo os modos de vida dominantes (coloniais, modernos e capitalistas) não podem ser vivenciadas por comunidades que possuem outros modos de vida: indígenas ou rurais, por exemplo.

Por tal perspectiva, os territórios reconhecidos como cidades hoje se caracterizam como um não-lugar aos indígenas, camponeses e demais comunidades que compõem o povo brasileiro, que nelas residem, mas são fragilizados pelo sistema econômico vigente - mesmo no Brasil, país que tem os primeiros como sua população local original e que ainda em 2015, teve identificadas pelo Instituto Brasileiro de Geografia e Estatística (IBGE), 104 regiões como rurais.

Tal cenário ocasiona e demanda uma importante discussão sobre as diversas formas de violência sofridas nas cidades por essas comunidades, o que por si só é capaz de fundamentar uma reflexão profunda acerca da necessidade de se instaurar novos modelos de cidades no país. No entanto, a necessidade de se realizar essa reflexão é ainda fortalecida e ao mesmo tempo, oportunizada pela crise civilizatória e ambiental atual (provocada pelo capitalismo e seu suporte ideológico calcado no individualismo e no racionalismo), a qual favoreceu a conquista de espaço por concepções de desenvolvimento distintas das do capitalismo e o surgimento de experiências ecossocioeconômicas. Ambas, em nosso entender, devem ter como consequência natural a promoção de discussões acerca da necessidade de (re)configuração de um tipo novo de cidades brasileiras.

Também defendendo a reconfiguração de cidades, Harvey (2014) aponta que

Nossa tarefa política, sugere Lefebvre, consiste em imaginar e reconstruir um tipo totalmente novo de cidade a partir do repulsivo caos de um desenfreado capital globalizante e urbanizador. Contudo, isso não pode ocorrer sem a criação de um vigoroso movimento anticapitalista cujo objetivo central seja a transformação da vida urbana do nosso cotidiano. (HARVEY, 2014, p.20). 


\title{
3. A reconfiguração de cidades brasileiras a partir do Bem Viver
}

Para nós, considerando essa concepção de Harvey - que condiciona a reconstrução de um tipo novo de cidade a um forte movimento anticapitalista que objetive transformar a vida urbana -, a reconfiguração de cidades brasileiras ou partes delas, pode ser pensada a partir do Bem Viver, ou seja, a partir da substituição na organização dessas cidades, da ideia de desenvolvimento pautado no estilo de vida dominante, no crescimento material sem fim - um caminho voltado para o "progresso" e tomado enquanto objetivo universal -, pela implantação de uma filosofia que busque uma harmonia entre o homem e a natureza e entre os próprios homens.

Como sustenta Acosta (2016),

\begin{abstract}
Não se pode mais sustentar o discurso do desenvolvimento, que, com suas raízes coloniais, justifica visões excludentes. Requeremos um discurso contra-hegemônico que subverta o discurso dominante e suas correspondentes práticas de dominação. E, igualmente, novas regras e lógicas de ação, cujo êxito dependerá da capacidade de pensar, propor, elaborar e, inclusive, indignar-se - globalmente, se for o caso. (ACOSTA, 2016, p.34)
\end{abstract}

Dando continuidade a essa defesa por mudanças, a qual também nós entendemos como necessária, Acosta (2016) afirma nas páginas seguintes de sua obra que, por propor harmonia com a natureza, relacionalidade, reciprocidade, solidariedade e complementariedade entre indivíduos e comunidades, com seu regresso a valores de uso e sua oposição ao conceito de acumulação perpétua, o Bem Viver abre as portas para a construção de um projeto emancipador para a formulação de alternativas de vidas - e, nós acrescentamos, consequentemente, para a reconfiguração de cidades.

Em conformidade com as ideias apresentadas por Acosta (2016), nos parece que, há grupos no Brasil que, aos poucos, têm começado a compreender que o crescimento baseado em inesgotáveis recursos naturais é equivocado e que a adoção do estilo de vida dominante em nosso país é inviável. A maioria das pessoas não só não têm alcançado o bemestar material como ainda têm sido afetadas em suas liberdades, identidades e até mesmo segurança.

É por isso que defendemos, em meio à atual crise do capitalismo, a luta por uma nova organização social a partir de uma reconfiguração de cidades brasileiras, de seus espaços e valores, e acreditamos que, sendo uma proposta de enfretamento à colonialidade do poder, questionadora do conceito eurocêntrico de bem-estar, pode a teorização do Bem Viver ser pensada como um dos princípios norteadores dessa luta, uma vez que, enquanto 
Um projeto que, ao haver somado histórias de lutas, de resistência e de propostas de mudanças, e ao nutrir-se de experiências locais, às que deverão somar-se contribuições provenientes de diversas latitudes, posiciona-se como ponto de partida para estabelecer democraticamente sociedades sustentáveis. (ACOSTA, 2016, p.40)

Concedendo o devido valor às experiências locais e à soma das histórias de lutas das comunidades, características da filosofia trazidas acima através de Acosta (2016), há quem fale em Bem Viveres, no plural, considerando que não existe um caminho universalmente traçado, sempre válido e eficiente, mas que a "solução" seria encontrada no caso concreto, nos diversos sujeitos, em suas variadas demandas e na aprendizagem coletiva. É com base nesse princípio que defendemos a desvinculação das cidades brasileiras às europeias, assim como a possibilidade de haver cidades com diferentes configurações no Brasil, de acordo com a história, valores e necessidades dos habitantes de cada uma delas.

\section{Conclusões}

Findamos essa breve reflexão reconhecendo que pensar em qualquer nível de superação do sistema capitalista, assim como em reconfiguração de cidades, parece algo utópico, sobretudo quando se faz a partir da filosofia do Bem Viver.

No entanto, a superação da forma como o capitalismo opera atualmente, das dimensões do colonialismo e das relações de exploração irresponsável dos recursos naturais no Brasil são necessárias, e não podem ocorrer sem que se passe pela reconfiguração das nossas cidades, local onde se tem de modo mais explicito os efeitos, tanto positivos quanto negativos, de tal sistema.

A filosofia do Bem Viver possibilita pensar em lugares onde os homens vivam em harmonia uns com os outros e com a natureza, de modo que, tê-la como norte em um processo que busque a reconfiguração das cidades, é objetivar a construção de lugares que sejam capazes de automanter-se e acolher pessoas que costumam viver em situações vulneráveis em nossas cidades atuais. Assim, trazer a discussão do Bem Viver para o cenário urbano, apesar do espanto inicial que possa gerar, se apresenta como pertinente e proveitoso, e em nosso entender, merce ser tratado com seriedade.

Isso, no entanto, não significa que defendamos que a filosofia do bem viver deve servir como norte à reconfiguração de toda e qualquer cidade brasileira. Sabemos que, no caso em questão, não se pode pensar em soluções prontas, sob o risco de se propor uma nova hegemonia ao invés de um ajustamento. Por isso, nossa proposta se limita a tentar contribuir com o desafio de pensar além do que já nos é dado, de construir horizontes libertadores para 
as cidades brasileiras, rompendo com os modelos que nos são impostos desde a Colônia e reconfigurando-as com base nas necessidades e valores de seus habitantes. Desse modo, temos a filosofia do Bem Viver, como dito, como uma alternativa pertinente e proveitosa de reconfigurar parte das cidades brasileiras e que merece ser discutida, mas não como a única.

\section{Referências}

ACOSTA, Alberto. O Bem Viver, São Paulo: Fundação Rosa Luxemburgo; Autonomia Literária; Elefante, 2016.

BOSI, Alfredo. Dialética da Colonização. São Paul: Companhia das Letras, $3^{\text {a }}$ edição, 1996.

COULANGES, Fustel de. A Cidade Antiga. São Paulo; Editora das Américas S.A. EDAMERIS, 1961

DEL NEGRI, André. A Divisão no Espaço Urbano. Belo Horizonte: Editora Fórum, 2012.

DILGER, Gerhard; PEREIRA, Jorge.Apresentação à edição brasileira. Ousar pensar "fora da caixa”. In: LANG, Miriam; DILGER, Gerhard; PEREIRA NETO, Jorge (Org.).

Descolonizar o Imaginário. Fundação Rosa Luxemburgo; Autonomia Literária; Elefante, 2016.

FANI, Ana O Espaço Urbano: Novos Escritos sobre a Cidade, São Paulo: FFLCH, 2007.

HARVEY, David. Cidades Rebeldes do Direito à cidade à revolução urbana. São Paulo: Martins Fontes, 2014

. Alternativas ao neoliberalismo e o direito à cidade. Novos Cadernos NAEA, v. 12, n 12, 2009. Disponível em:

http://periodicos.ufpa.br/index.php/ncn/article/viewFile/327/513. Acesso em: 13 de abril de 2016.

IBANEZ, Mario Rodriguez. Ressignificando a cidade colonial e extrativista. In: LANG, Miriam; DILGER, Gerhard; PEREIRA NETO, Jorge (Org.). Descolonizar o Imaginário. Fundação Rosa Luxemburgo; Autonomia Literária; Elefante, 2016.

LANG, Miriam. Introdução. Alternativas ao desenvolvimento. In: LANG, Miriam; DILGER, Gerhard; PEREIRA NETO, Jorge (Org.). Descolonizar o Imaginário. Fundação Rosa Luxemburgo; Autonomia Literária; Elefante, 2016.

LEFEBVRE, Henry. O direito à cidade. São Paulo: Centauro. [1968] 2008.

PONTES JUNIOR, Felício de Araújo; BARROS, Lucivaldo Vasconcelos. A natureza como sujeito de direitos. In: LANG, Miriam; DILGER, Gerhard; PEREIRA NETO, Jorge (Org.). Descolonizar o Imaginário. Fundação Rosa Luxemburgo; Autonomia Literária; Elefante, 2016.

Portal do Instituto Brasileiro de Geografia e Estatística (IBGE). Disponível em http://www.ibge.gov.br/home/geociencias/geografia/default_regioes_rurais.shtm 
Acesso em: 22 de abril de 2017.

WILLIAMS, Raymond. O campo e a cidade. Na história e na literatura; São Paulo: Companhia das Letras [1973] 1990. 